\title{
Effect of imposed drought on seedlings growth, water use efficiency and survival of three arid zone species (Acacia tortilis subsp raddiana, Salvadora persica and Leptadenia pyrotechnica)
}

\author{
Elfeel $\mathrm{AA}^{1}$ and Mohamed L. Al-Namo ${ }^{2}$ \\ ${ }^{1}$ College of Forestry and Range Science - Sudan University of Science and Technology \\ Faculty of Meteorology, Environment and arid land Agriculture - King Abdulaziz University \\ ${ }^{2}$ Graduate Student, College of Forestry and Range Science
}

\begin{abstract}
Survival of seedlings in arid zone plantation is strongly affected by water stress and drought conditions. Many tree species are able to develop adaptive mechanisms in response to drought stress. The aim of this study was to assess the effect of imposed drought stress on seedlings growth, water use efficiency and survival of three arid zone species (Acacia tortilis subsp raddiana, Salvadora persica and Leptadenia pyrotechnica). Three successive drought cycles were imposed, to a five months old seedlings of the three species. At the end of the drought cycles treatment, water was withheld from both well watered and stressed seedlings and survival was counted until all seedlings wilted out. Growth traits and WUE were measured in drought treated and untreated seedlings. The results showed that imposed drought stress enhanced adaptive traits on these seedlings resulting in better survival. Drought treatment significantly reduced growth traits and WUE in the three species and increased root to shoot ratio and survival. The results pointed out that drought stress conditioning enhanced adaptive traits for these species. However, response was varied among species. S. persica showed better growth than $A$. tortilis and $L$. pyrotechnica, alternatively survival was better in $A$. tortilis and $L$. pyrotechnica than S. Persica. These results may suggest that in severe drought-prone sites $A$. tortilis and L. pyrotechnica are preferred.
\end{abstract}

Keyword: drought cycles, adaptive response, biomass partitioning, WUE, survival.

\section{INTRODUCTION}

Growth and survival of trees in dry land plantation largely depend on the selection of suitable species and populations that are drought tolerant. Drought and water stress are the main factors limiting survival during plantation establishment (Garau, 2008). So, understanding of seedlings responses to water and drought stress will provide the fundamental basis for developing successful plantations in arid zone under drought and water stress conditions. Plants in arid lands have developed a wide diversity of morphological and physiological adaptive drought tolerance mechanisms (Kozlowski and Pallardy, 2002). Of these common adaptive mechanisms are changes in root/ shoot ratio, growth rate and water use efficiency (Beadle et al, 1993). Many studies showed that drought conditioning can enhance these adaptive traits for drought tolerance in tree species (Elfeel et al., 2007; Aranda, et al., 2005; Greg and Zhang, 2001; Mayne et al., 1994). Interspecific variation among species in biomass partitioning and water use efficiency was recorded (Chunying et al.,
\end{abstract}

2005). Seedlings previously exposed to water stress undergo less injury from drought and transplanting than the unexposed seedlings indicating tolerance for dehydration has been increased (levitt, 1980; Kozlowski and Pallardy 1997). Water use efficiency (WUE), represents one of the most important factors in plants tolerance to drought. Many methods were used for WUE estimation. Method based on the ratio of biomass production to water transpired (according to evaporative loss from pots) was used by many authors (Chunying et al., 2005; Martin and Thorstenson, 1988).

Currently more than $50 \%$ of land area of the Sudan is considered as dry lands (Nasroon, 2000). From the remaining lands about $30 \%$ is low rainfall savannah. According to the land and water research centre, the decrease of land area in this zone reached approximately $19 \%$ during the last couple of years (Omar, 2000). This is mainly due to the fact that most of land use systems including mechanized farming and grazing is concentrated in this zone. Therefore, for successful development of these lands, choice of 
suitable species that withstand these changing environments is highly needed. Many tree species are found grown in the arid land of Sudan. Among these, the most promising species for arid land afforestation are $A$. tortilis subsp raddiana, S. persica and $L$. pyrotechnica. In addition to their wide range of uses such as fodder, fuel and sand dune stabilization, these three species are widely distributed in most of the dry lands of Sudan and many parts of Africa and middle east (Arbonnier, 2004).

Salvadora persica is an evergreen perennial halophyte capable of growing under extreme conditions of dry environments and saline soils (Maggio et al, 2000). Moreover, it can grow successfully in saline and alkaline soil, yielding large amounts of vegetable oil of high industrial importance (Muppala et al, 2008). According to Alamin (1990), A. tortilis occurs in the desert and semi desert plains of northern and central Sudan. It is wide spread a long seasonal valleys and streams. Outside Sudan it is found from Senegal to Cameroon, as far as Somalia, Tropical Africa, North Africa, Middle east and Arabia (Arbonnier, 2004). Leptadenia pyrotechnica is a shrub common on dry sand dunes of the semi desert zone of the Sudan, Sahelian and Saharan areas, on sandy soil (Arbonnier, 2004; Alamin, 1990).

The three species are extremely adapted to a wide range of environments in arid and semi arid zones. This capacity of growth under different arid environments indicates that these species can develop different adaptive mechanism to these environments. First year survival is common problem associated with afforestation in arid zone. Knowledge of adaptive responses of these species to drought will assist to address this problem.

Therefore, the objective of this study was to assess the adaptive morphological traits of three major arid zone species (Acacia tortilis subsp raddiana, Salvadora persica and Leptadenia pyrotechnica) to imposed drought stress. Specifically, to investigate the effect of three successive drought stress cycles on shoot length, root length, root collar diameter, shoot and root dry weights, root/shoot ratio, water use efficiency and survival of the three species.

\section{MATERIALS AND METHODS}

The Treatments and Design: The experiment was carried out at the College of Forestry and Range Science Nursery. Seedlings were raised in polythene bags $30 \times 20 \mathrm{~cm}$ (when flat) filled with a mixture of clay and sand (50:50 ratio). The seedlings were watered with hand watering can to field capacity every two days. After four months of growth seedlings of same height were selected per each species and divided into two treatments. Treatment one (normal irrigation) and treatment two (stress cycles). The design used was a split plot design with three replicates. The irrigation treatments represents the main plots and the species represents the subplots. The seedlings were then watered normally for one month for recovery and establishment, after which the treatments were applied. In treatment one the seedlings were watered normally to field capacity, while in treatment two seedlings were watered to field capacity followed by subsequent water withheld. The end of the drought stress cycle was indicated when some seedlings show sign of wilting, after which the seedlings were re-watered for recovery. Three drought stress cycles were applied. The first stress cycle took 9 days, cycle two ended in 12 days and cycle three took 14 days, with three days of watering as a recovery after each cycle. At the end of the drought stress cycles, water was withheld from both treatments and seedlings mortality was counted every week until all seedlings were died.

Growth traits: Seedlings growth traits (shoot height, root collar diameter, root length and dry weights) were measured three times. Before treatments application, at the end of stress cycles and at the end of survival count, respectively. Leaves dry weight were measured at the beginning and end of stress treatments.

Plant water use efficiency (WUE): Plant water use efficiency (WUE $\mathrm{WL}_{\mathrm{L}}$ ) was calculated as the ratio of the total seedlings dry weight to the cumulative amount of water transpired. Whole plant water loss (WL), through transpiration was measured in five potted seedlings for each species and per each treatment. The pots were watered and weighed and left stand for 24 hours and then reweighed. Three blank pots, the same as the experimental pots but without plants, were incorporated to correct for direct evaporation from the pots. Water loss (WL) was calculated as the difference in pot weight over a period of $24 \mathrm{~h}$ minus average weight of the blank pots. Seedlings dry weight was measured at the beginning and end of stress cycles.

Survival: At the end of drought cycles seedlings were watered for recovery, after which water was withheld from both normally watered and stressed seedlings. Then mortality was counted every week for five weeks. The seedling was scored dead when all its leaves were completely wilted. 
Data analysis: Two way analysis of variance was carried out to determine the significance of the main treatments. Duncan's multiple range test was used to separate between means. SAS statistical analysis system (SAS, V8, 2000) was used for data analysis.

\section{RESULTS AND DISCUSSION}

The results showed a very high effect of imposed drought stress treatments on seedlings growth and survival (Table 1). Stress treatment had induced drought adaptive traits in the seedlings resulting in higher survival of stressed seedlings over normally watered seedlings for all species. Stressed seedlings start dying one week later and survived for longer time than normally watered seedlings (table 3). Increase in survival, as response to drought stress had been reported by many authors (Koslwoski and Pollardy, 2002; Elfeel et al, 2007 ). Best survival under water stress conditions was recorded in $A$. tortilis (Table 3 ). In addition to that, $A$. tortilis had higher biomass production and significantly higher root to shoot ratio (table 2). This indicates that the Table 1: Summary of the ANOVA Results for the effect of the treatment, species and interactions on seedlings growth of Acacia tortilis subsp raddiana, Salvadora persica and Leptadenia pyrotechnica.

\begin{tabular}{|l|l|l|l|l|}
\hline Parameter & Factor & d.f. & F. & P. \\
\hline Shoot length & Treatment & 1 & 2.03 & 0.1 \\
& Species & 2 & 360.09 & 0.0001 \\
& TRT`Spp Interaction & 2 & 1.31 & 0.2 \\
\hline Root collar diameter & Treatment & 1 & 51.47 & 0.0001 \\
& Species & 2 & 22.62 & 0.0001 \\
& TRT*Spp Interaction & 2 & 0.05 & 0.9 \\
\hline Root length & Treatment & 1 & 5.35 & 0.02 \\
& Species & 2 & 17.32 & 0.0001 \\
& TRT*Spp Interaction & 2 & 0.03 & 0.9 \\
\hline Shoot dry weight & Treatment & 1 & 53.38 & 0.0001 \\
& Species & 2 & 61.36 & 0.0001 \\
& TRT*Spp Interaction & 2 & 12.39 & 0.0001 \\
\hline Root dry weight & Treatment & 1 & 24.11 & 0.0001 \\
& Species & 2 & 104.67 & 0.0001 \\
& TRT`Spp Interaction & 2 & 18.08 & 0.0001 \\
\hline Leaves dry weight & Treatment & 1 & 9.6 & 0.002 \\
& Species & 2 & 176.2 & 0.0001 \\
& TRT*Spp Interaction & 2 & 2.3 & 0.1 \\
\hline
\end{tabular}

efficiency of this species under drought conditions is higher than the two other species.

The significance of the effect of the treatment and species on growth traits was very high $(p=<0.01)$. However, treatments time species interaction was not significant in most of the traits indicating that species ranking was the same in both treatments (Table 1 ). In general seedlings had higher values in growth traits in normally watered seedlings than stressed seedlings, except root to shoot ratio, which was higher under stress condition (Table 2). The higher values of root to shoot ratio in all species under water stress condition means that under drought conditions these species increase the allocation of photosynthate towards the roots to increase surface area for water absorption. Changes in root to shoot ratio in response to water stress, represents one of the most adaptive mechanisms in plants tolerance to water stress (Gorka et al., 2010; Drunasky and Struve, 2005; Beadle et al, 1993). 
Drought stress reduced water use efficiency in all studied species (Fig. 1). This result will not mean that under drought conditions, plants increase their water loss resulting in lower values of WUE. In fact whole plants water loss was lower under drought conditions in all the species. The drop in WUE under drought conditions was mainly due to the fact that drought stress treatment resulted in a remarkable reduction in biomass for the three species as indicated in (Table 2 ), leading to lower values of WUE. A reduction in biomass and WUE as a resulted of water stress was evidenced by (Blum, 2005). However, the level of reduction varies between species (Fig. 1). Higher
WUE was reported for $S$. persica. This was negatively associated with survival rate, as mortality trend was higher in this species than the other two species. This means that the higher WUE observed in this species was reflected in better growth.

The results revealed that drought stress conditioning enhanced adaptive morphological traits for these species. However, response was various among species. S. persica showed better growth than the $A$. tortilis and $L$. pyrotechnica, alternatively survival was better in $A$. tortilis and $L$. pyrotechnica than $S$. Persica.

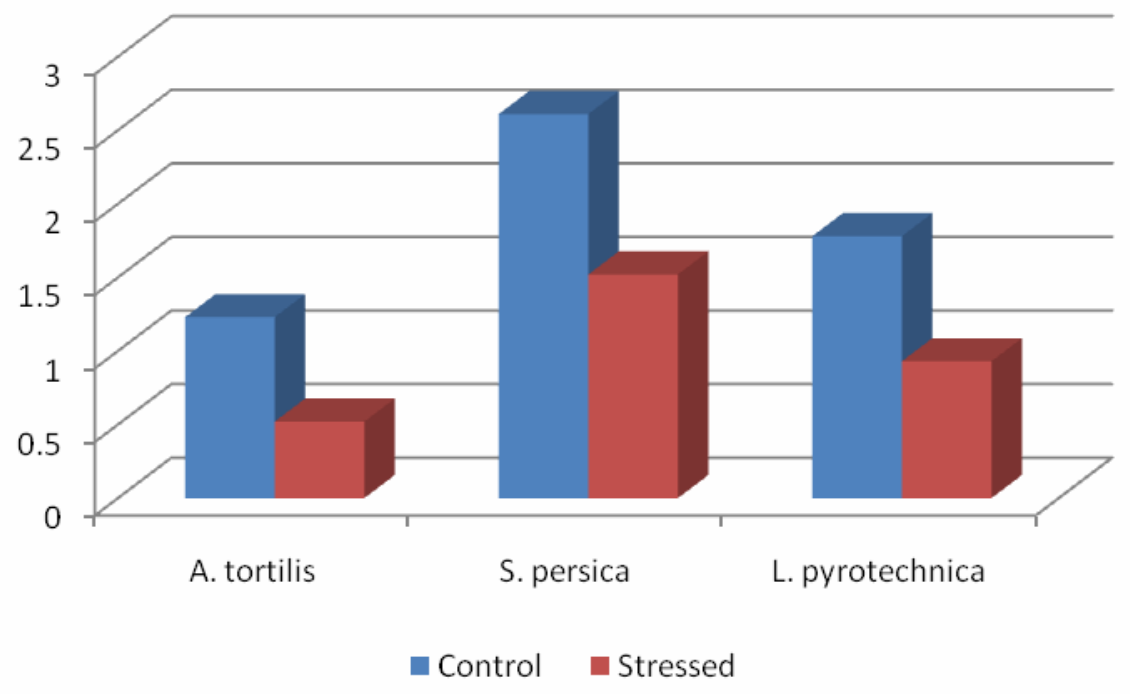

Fig. 1: Effect of drought stress on water use efficiency of tortilis subsp raddiana, Salvadora persica and Leptadenia pyrotechnica seedlings. 
Agric. Biol. J. N. Am., 2011, 2(3): 493-498

Table 2: Effect of drought stress cycles treatment on seedlings growth traits of Acacia tortilis subsp raddiana, Salvadora persica and Leptadenia pyrotechnica

\begin{tabular}{|c|c|c|c|c|c|c|c|c|c|c|c|c|c|c|}
\hline \multirow[t]{2}{*}{ Species } & \multicolumn{2}{|c|}{ Shoot length $(\mathrm{cm})$} & \multicolumn{2}{|c|}{$\begin{array}{l}\text { Root length } \\
(\mathrm{cm})\end{array}$} & \multicolumn{2}{|c|}{$\begin{array}{l}\text { Root collar diameter } \\
(\mathrm{cm})\end{array}$} & \multicolumn{2}{|c|}{$\begin{array}{l}\text { Shoot dry weight } \\
\text { (grams) }\end{array}$} & \multicolumn{2}{|c|}{$\begin{array}{l}\text { Root dry weight } \\
\text { (grams) }\end{array}$} & \multicolumn{2}{|c|}{ Leaves dry weight } & \multicolumn{2}{|c|}{ Root/shoot ratio } \\
\hline & Normal & Stressed & Normal & Stressed & Normal & stressed & normal & Stressed & normal & stressed & Normal & stressed & normal & Stressed \\
\hline A. tortilis & $55.9^{b}$ & $53.2^{b}$ & $44.3^{\mathrm{a}}$ & $31.1^{a}$ & $0.47^{b}$ & $0.37^{b}$ & $4.3^{b}$ & $2.0^{b}$ & $2.9^{\mathrm{a}}$ & $1.5^{\mathrm{a}}$ & $0.57^{b}$ & $0.14^{b}$ & $0.67^{a}$ & $0.75^{a}$ \\
\hline S. persica & $54.2^{b}$ & $42.4^{\mathrm{C}}$ & $45.8^{\mathrm{a}}$ & $36.2^{\mathrm{a}}$ & $0.46^{b}$ & $0.45^{b}$ & $3.6^{b}$ & $2.4^{b}$ & $1.3^{b}$ & $1.1^{b}$ & $1.38^{\mathrm{a}}$ & $1.27^{\mathrm{a}}$ & $0.36^{b}$ & $0.46^{b}$ \\
\hline L. pyrotechnica & $73.2^{a}$ & $71.9^{\mathrm{a}}$ & $29.1^{\mathrm{b}}$ & $27.1^{\mathrm{a}}$ & $0.54^{\mathrm{a}}$ & $0.49^{a}$ & $5.9^{\mathrm{a}}$ & $3.4^{\mathrm{a}}$ & $0.8^{\mathrm{b}}$ & $0.6^{\mathrm{C}}$ & $0.08^{b}$ & $0.024^{b}$ & $0.14^{\mathrm{C}}$ & $0.18^{\mathrm{C}}$ \\
\hline
\end{tabular}

Means with same letter in the same column are not significantly different (at $p=0.05$ ), using Duncan's multiple range test.

Table 3: Effect of drought stress treatment on mortality percent of Acacia tortilis subsp raddiana, Salvadora persica and Leptadenia pyrotechnica

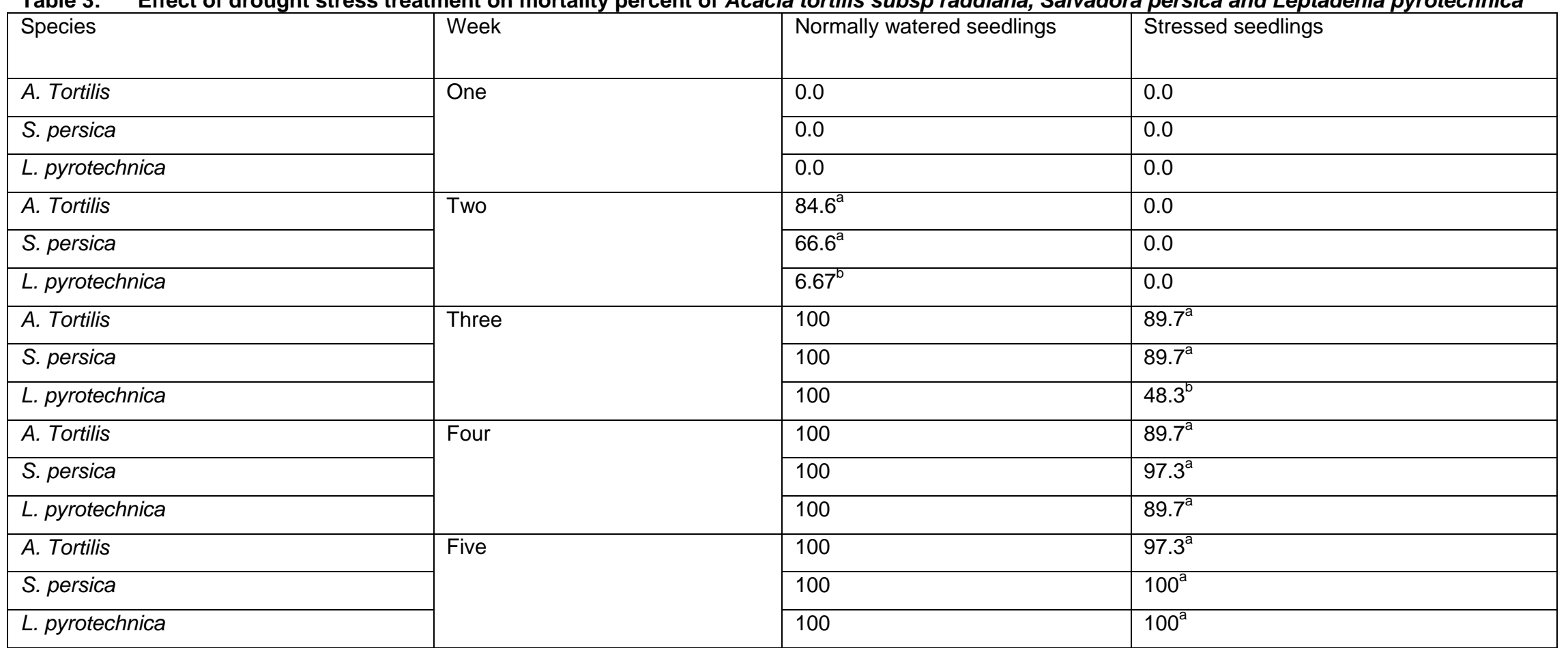

Means with same letter in the same column are not significantly different (at $\mathrm{p}=0.05$ ), using Duncan's multiple range test. 


\section{CONCLUSION}

Drought conditioning enhanced growth adaptive traits in the three species, resulting in increased survival over untreated seedlings. Survival was better in $A$. tortilis and L. pyrotechnica, while growth is better in $S$. Persica. This results may indicate that under very severe drought-prone sites $A$. tortilis and $L$. pyrotechnica are the choice.

\section{REFERENCES}

Alamin HM. 1990. Trees and shrubs of the Sudan. Etheca press, 8 Richmond Road Exeter EX44 JA, The Netherland.

Aranda I, L. Castro, M. Pardos, L. Gil and J.A. Pardos. 2005. Effects of the interaction between drought and shade on water relations, gas exchange and morphological traits in cork oak (Quercus suber L.) seedlings. Forest Ecology and Management 210 , $117-129$

Arbonnier M 2004. Trees, Shrubs and Lianas of West African Dry Zones. CIRAD, MARGRAF PUBLISHERS GMBH.

Beadle CL. MM Ludlow and JL Honeysett 1993. Water relations. In Hall DO, Scurlock JMO, BolharNordenkampf HR, Leegood RC and Long SP (editors) . Photosynthesis and production in a changing environment: A field and laboratory manual. Chapman and Hall, London, UK.

Blum A 2005. Drought resistance, water-use efficiency, and yield potential-are they compatible, dissonant, or mutually exclusive. Australian Journal of Agricultural Research, 56, 1159-1168

Chunying Yin, Xiang Wang, Baoli Duan, Jianxun Luo, Chunyang Li. 2005. Early growth, dry matter allocation and water use efficiency of two sympatric Populus species as affected by water stress. Environmental and Experimental Botany 53, 315-322

Drunasky N and DK Struve . 2005. Quercus macrocarpa and Q. Prinus physiological and morphological responses to drought stress and their potential for urban forestry. Urban Forestry \& Urban Greening 4 , 13-22

Elfeel AA, Warag EL and Musnad HA 2007. Response of Balanites aegyptiaca (L.) Del. seedlings from varied sources to imposed drought stress cycles. Discovery and Innovation 19(4). 319 - 325.

Garau A.M, J.H. Lemcoff, C.M. Ghersa and C.L. Beadle 2008. Water stress tolerance in Eucalyptus globulus Labill. subsp. Maidenii (F. Muell.) saplings induced by water restrictions imposed by weeds. Forest Ecology and Management 255, 2811-2819
Gorka Erice, Sa'ıd Louahlia, JuanJos Irigoyen, Manuel Sanchez-Diaz, Jean-Christophe Avice 2010. Biomass partitioning, morphology and water status of four alfalfa genotypes submitted to progressive drought and subsequent recovery. Journal of Plant Physiology 167, 114-120

Gregg B.M. and J.W. Zhang 2001. Physiology and morphology of pinus silvestris seedlings from diverse sources under cyclic drought stress. Forest Ecology and Management, 154, 131 - 139.

Kozlowski, TT and S.G. Pallardy 1997. Physiology of woody plants. $2^{\text {nd }}$ ed. Academic Press. San Diego. CA.

Kozlowski, TT and S.G. Pallardy 2002. Acclimation and adaptive responses of woody plants to environmental stresses. The Botanical review 68(2): 270-234.

Levitt, J. 1980. Responses of plants to environmental stresses. $2^{\text {nd }}$ ed Volume 2. Academic Press. New York.

Maggio A, Muppala P. Reddy and Robert J. Joly 2000. Leaf gas exchange and solute accumulation in the halophyte Salvadora persica grown at moderate salinity. Environmental and Experimental Botany 44, 31-38

Martin B and YR. Thorstenson 1998. Stable Carbon Isotope Composition (613C), Water Use Efficiency, and Biomass Productivity of Lycopersicon esculentum, Lycopersicon pennellii, and the F1 Hybrid. Plant Physiol. 88, 213-217

Mayne MB, Subramanian M, Blake T, Coleman JR and Blumwald E. 1994. Changes in protein synthesis during drought conditioning in roots of jack pine seedlings (Pinus banksiana lamb.). Tree Physiology 14: 5049-519.

Muppala P. Reddy, Mukesh T. Shah, Jinalal S. Patolia 2008. Salvadora persica, a potential species for industrial oil production in semiarid saline and alkali soils. industrial crops and products $28,273-278$

Nasroon T. H. 2000. Principles of Forestry and its applications in arid zone. Dar Al-Kutub for publishing and distribution, Riyadh, KSA.

Omar. M. A. 2002. Research and development (R\&D) profile for Sudan. Water harvesting Institute (ARC) Agricultural Research Corporation, Sudan.

SAS Institute Inc. 2000. SAS Statistical analysis, Version 8, SAS institute Inc., Cary, NC 27513, USA. 